\title{
ADSORÇÃO DE IMUNOGLOBULINAS G EM SILICAS MESOPOROSAS DO TIPO SBA 15
}

\author{
T. N. B. RODRIGUES ${ }^{1}$, S. O. SANTOS, D. R. GONDIM ${ }^{1}$, E. V. GARCIA ${ }^{2}$, J. A. CECÍLIA ${ }^{2}$, \\ E. R. CASTELON ${ }^{2}$, D. C. S. AZEVEDO ${ }^{1}$ e I. J. da SILVA JÚNIOR ${ }^{1}$ \\ ${ }^{1}$ Universidade Federal do Ceará, Departamento de Engenharia Química \\ ${ }^{2}$ Universidad de Malagá, ES \\ E-mail para contato: Ivanildo@gpsa.ufc.br
}

\begin{abstract}
RESUMO - O presente trabalho teve como objetivo sintetizar sílicas mesoporosas do tipo SBA 15 com e sem zircônio, a fim de avaliar a adsorção da proteína IgG (Imunoglobulinas do isotipo G) nesses materiais. O SBA 15 foi sintetizado através do tratamento hidrotérmico e incorporado com zircônio em três diferentes razões molares de $\mathrm{Si} / \mathrm{Zr}$ (5, 10 e 20). Os ensaios em bateladas consistiram na avaliação da influência do $\mathrm{pH}$, na cinética e isoterma de adsorção. Os resultados mostraram que a adsorção de $\mathrm{IgG}$ foi influenciada pelo $\mathrm{pH}$, sendo o $\mathrm{pH} 7,0$ o de maior adsorção em tampão fosfato de sódio $25 \mathrm{mM}$. O tempo de equilíbrio foi de $2 \mathrm{~h}$ com o SBA 15 sem zircônio e $7 \mathrm{~h}$ para os outros três materiais com zircônio. E o adsorvente SBA 15 sem zircônio apresentou a maior quantidade máxima de adsorção de IgG. $\mathrm{O}$ modelo de Langmuir se ajustou bem aos dados experimentais.
\end{abstract}

\section{INTRODUÇÃO}

As SBA-15 são materiais mesoporosos com estrutura altamente organizada à base de silicatos compostas por uma rede de canais e poros com arranjo hexagonais. Em geral, apresentam poros com tamanhos bem definidos na escala nanométrica, além de estabilidade térmica e hidrotérmica (Tsoncheva et al., 2006).

É conferida as SBA's a possibilidade de manipulação química e alteração de sua superfície de forma seletiva, tornando favorável seu uso em processos de adsorção, catálise, nanotecnologia. O controle de algumas propriedades, tais como fases nanométricas e organização da mesoestrutura, fornecem ao material uma diversidade de aplicações e funcionalidades (Santos, 2013).

A grande aplicabilidade da proteína Imunoglobulina do isotipo $\mathrm{G}(\mathrm{IgG})$ em tratamentos de câncer, doenças infecciosas, entre outras, exige um alto grau de pureza e uma quantidade significativa da proteína (Burnouf et al., 2001). As técnicas utilizada para os processos de bioseparação tem por objetivo alcançar a pureza e a recuperação necessárias aliadas ao não comprometimento da atividade das proteínas. 
Devido a sua capacidade de permitir alterações em sua química superficial (Tsoncheva et al., 2006) aliadas a característica de incorporar moléculas orgânicas, a SBA-15 foi utilizada no estudo da adsorção dessa proteína.

Este trabalho possuiu como objetivo analisar quais as circunstâncias em que a adsorção da proteína seria favorecida e qual a influência da inserção de zircônio, em diferentes proporções, à SBA-15. Foram realizados estudos de $\mathrm{pH}$, cinética e isoterma de adsorção com a proteína $\operatorname{IgG}$ em batelada.

\section{MATERIAIS E MÉTODOS}

\subsection{Materiais}

Imunoglobulinas do isotipo G (IgG) obtidos da Sigma-Aldrich (EUA). Os outros reagentes utilizados foram de grau analítico e para o preparo das soluções foi utilizado água ultrapura MiliQ (Milipore, EUA).

\subsection{Síntese da SBA-15}

A síntese das sílicas mesoporosas do tipo SBA 15 com diferente acidez foi realizada conforme metodologia descrita por Fluvio et al. (2005) com algumas modificações. Inicialmente, o plurônio (P123) foi dissolvido em $\mathrm{HCl} 1,7 \mathrm{M}$ sob agitação magnética até dissolução completa do plurônio, em seguida o trimetilbenzeno (TMB) foi adicionado. Após 30 minutos de agitação, foi incorporada a fonte de sílica (TEOS) e de zircônio (propóxido de zircônio, $\mathrm{Zr}(\mathrm{OCH} 2 \mathrm{CH} 2 \mathrm{CH} 3) 4)$, gota a gota. $\mathrm{O}$ material foi preparado variando a razão molar de $\mathrm{Si} / \mathrm{Zr}$ de 20, 10 e 5. Quanto menor a razão maior quantidade de zircônio em relação a silício. O processo manteve-se sob agitação durante $24 \mathrm{~h} \mathrm{a} 40{ }^{\circ} \mathrm{C}$. Para o tratamento hidrotérmico, os materiais foram transferidos para um autoclave e aquecida a $100{ }^{\circ} \mathrm{C}$ durante $72 \mathrm{~h}$. No final do processo realizou-se a calcinação do material sob a temperatura de $550{ }^{\circ} \mathrm{C}$ por $6 \mathrm{~h}$ com uma taxa de aquecimento de $1^{\circ} \mathrm{C} / \mathrm{min}$.

\subsection{Métodos}

Efeitos do $\mathrm{pH}$, cinética e isoterma de adsorção: Para a realização dos ensaios de adsorção foi utilizado um sistema de agitação rotatório (TECNAL, modelo TE-165) a 18 rpm. Os ensaios foram realizados em duplicata, a uma temperatura de $22^{\circ} \mathrm{C}$. Foram postos em tubos de acrílico, juntamente com $3 \mathrm{ml}$ de solução, $15 \mathrm{mg}$ de SBA-15 (sem Si/Zr e com Si/Zr nas proporções 5, 10 e 20). A faixa de $\mathrm{pH}$ estudada foi de 4,0 a 8,0, utilizando os tampões acetato de sódio e fosfato de sódio, com molaridade de $25 \mathrm{mM}$. Permanecendo sob agitação por duas horas, para a cinética de adsorção foi utilizada a concentração de $1 \mathrm{mg} / \mathrm{mL}$ de $\operatorname{IgG}$ e o tempo de análise variou de 5 a $480 \mathrm{~min}$. Para a isoterma de adsorção foram utilizadas concentrações de proteína 0,5 a $6,0 \mathrm{mg} / \mathrm{mL}$. Em seguida, as amostras foram coletadas e postas para centrifugar em uma microcentrífuga (CT-15000R CIENTEC) por 10 min com rotação igual a 10000 rpm e a absorbância de cada amostra foi lida. A partir de uma curva de 


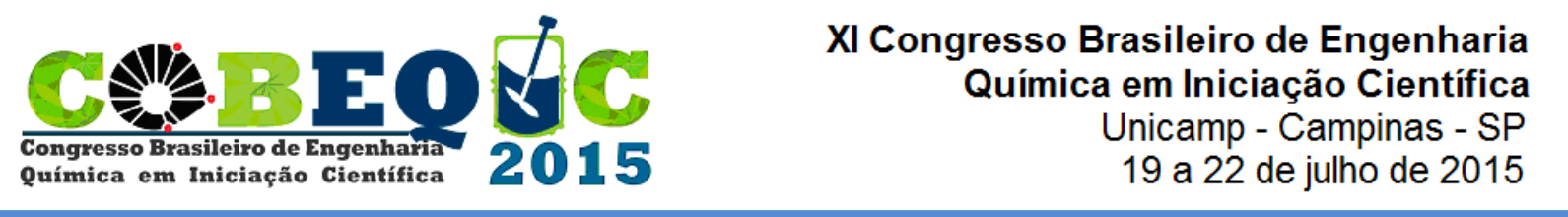

calibração previamente obtida, esses valões de absorbância foram convertidos para concentração.

Modelos de ajuste: Foi utilizado o modelo de ajuste de Langmuir representado pela equação 1. O modelo de Langmuir fornece os parâmetros de ajuste: quantidade máxima de adsorção $\left(Q_{M A X}\right)$ e a constante " $K_{D}$ ” que indica a afinidade da biomolécula pelo adsorvente.

$$
q=\frac{Q_{M A X} C_{E Q}}{K_{D}+C_{E Q}}
$$

\section{RESULTADOS E DISCUSSÕES}

\subsection{Estudo do pH e cinética de adsorção}

A adsorção de IgG nos quatro materiais (SBA 15, SBA 15 - Zr5, SBA 15 - Zr10 e SBA 15 - Zr20) foram estudadas nos tampões acetato e fosfato de sódio $25 \mathrm{mM}$. Importante lembrar que o ponto isoelétrico ( $\mathrm{pI}$ ) é o $\mathrm{pH}$ onde há um balanceamento de cargas igualitário da proteína e normalmente, nesse $\mathrm{pH}$ ocorre a maior adsorção. Para a proteína $\operatorname{IgG}$ o pI é variável entre 6,3 e 9,0 (Bresolin et al., 2010). Os ensaios em batelada foram realizados com intuito de avaliar a influência do pH na adsorção da IgG nos diferentes materiais mesoporosos e definir sob quais condições ocorre a maior adsorção, como pode ser observado na Figura 1.

Figura 1 - Influência do pH na adsorção de IgG com os materiais: SBA 15, SBA 15 Zr-5,

SBA 15 Zr-10 e SBA 15 Zr-20.

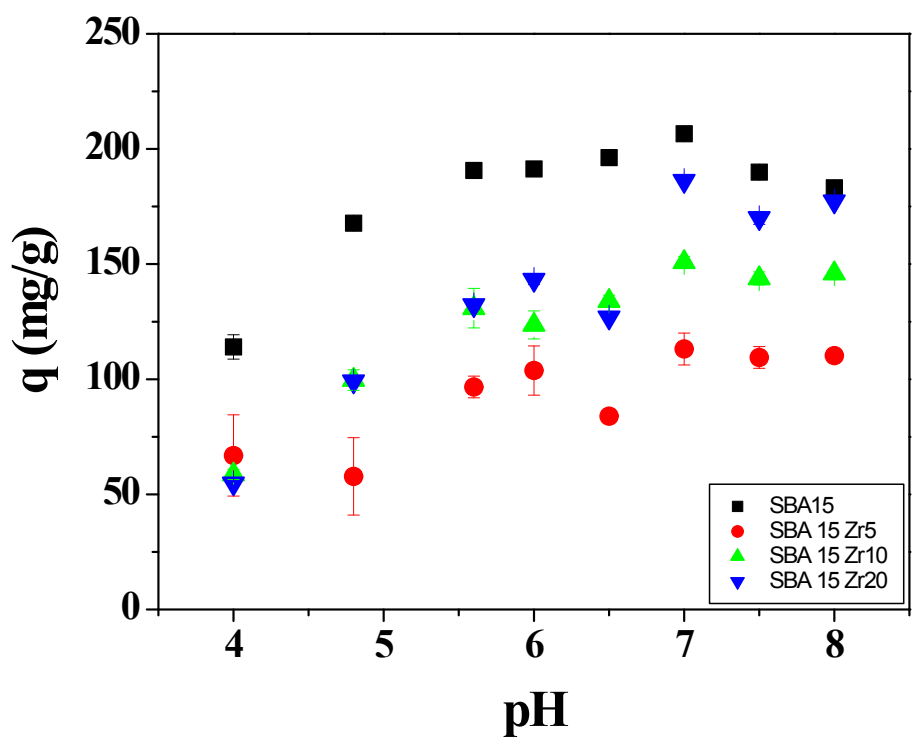


Verificou-se que a quantidade de IgG adsorvida nos quatro materiais aumentou com o aumento do $\mathrm{pH}$, sendo que no $\mathrm{pH} 7,0$, com o tampão fosfato de sódio, ocorreu a maior quantidade adsorvida de IgG em todos os materiais utilizados. Portanto, fixou-se esse $\mathrm{pH}$ $(7,0)$ para os ensaios de cinética e isoterma de adsorção. Observou-se que o SBA 15 sem zircônio apresentou maior quantidade adsorvida de $\operatorname{IgG}(\mathrm{em} \mathrm{pH} \mathrm{7,0),} \mathrm{em} \mathrm{torno} \mathrm{de,} \mathrm{206,6}$ $\mathrm{mg} / \mathrm{g}$, enquanto que a quantidade adsorvida dos outros três materiais foram 113,1, 150,8 e 186,2 mg/g, respectivamente para SBA 15 Zr-5, SBA 15 Zr-10 e SBA 15 Zr-20.

A Figura 2 apresenta a cinética de adsorção de $\operatorname{IgG}$ nos quatro materiais estudados. Observou-se que com o SBA 15 sem zircônio a adsorção ocorre rapidamente alcançando o equilíbrio em apenas 1 h. Para os SBA's 15 acrescido com zircônio verificou-se uma adsorção mais lenta necessitando de aproximadamente $7 \mathrm{~h}$ para alcançar o equilíbrio. Portanto, para os ensaios de isoterma de adsorção fixou-se o tempo de $2 \mathrm{~h}$ para o SBA 15 e $7 \mathrm{~h}$ para os três materiais (SBA 15 Zr-5, SBA 15 Zr-10 e SBA 15 Zr-20) com zircônio.

Figura 2 - Perfil da cinética de adsorção de IgG com quatro materiais em tampão fosfato de sódio $\mathrm{pH} 7,0$.

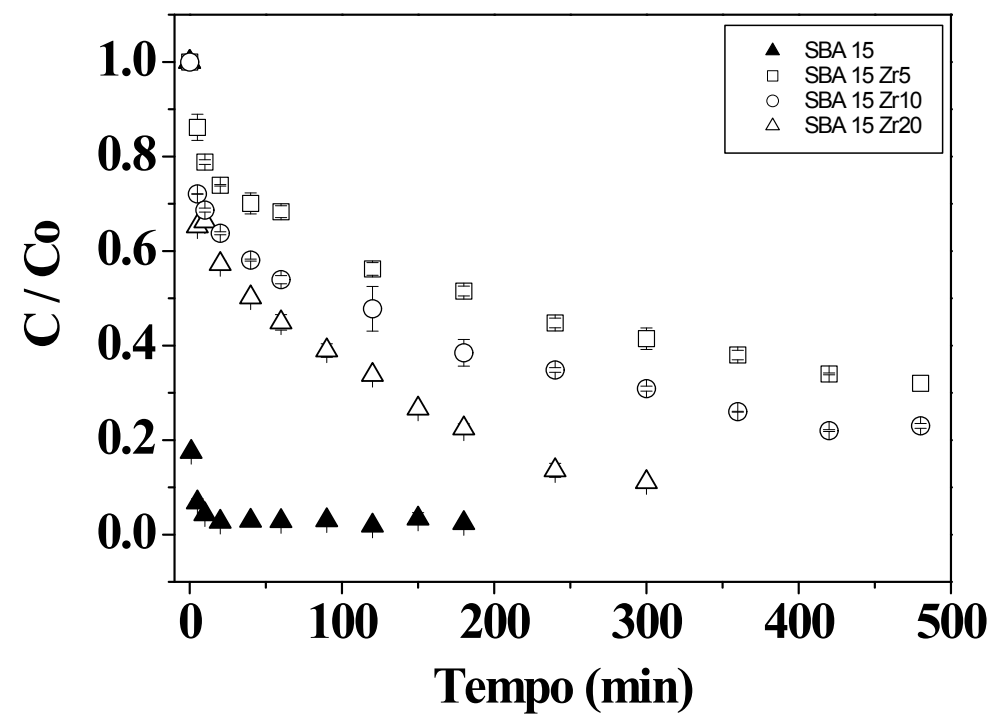

\subsection{Isoterma de Adsorção}

A Figura 3 apresenta os perfis de isoterma de adsorção de IgG nos quatro materiais. Observou-se que o SBA 15 sem zircônio teve maior quantidade adsorvida de IgG com relação aos materiais com zircônio. Outra informação importante obtida pelas isotermas de adsorção foi que à medida que aumentou a quantidade de zircônio no SBA 15 a quantidade de IgG adsorvida foi diminuindo. A quantidade adsorvida de IgG dos três materiais seguiu a seguinte sequência: SBA 15 Zr-5 < SBA 15 Zr-10< SBA 15 Zr-20. De acordo com os parâmetros de ajuste encontrados com o modelo de Langmuir a quantidade máxima com SBA 15 sem 


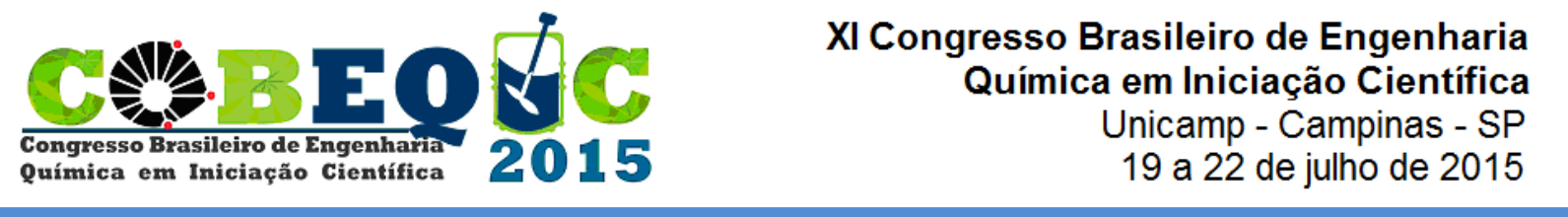

átomos de zircônio foi de $688,9 \mathrm{mg} / \mathrm{g}$ e para os materiais com zircônio a quantidade máxima de adsorção ficou $350 \mathrm{mg} / \mathrm{g}$, como pode ser observado na Figura 3.

Figura 3 - Perfis da Isoterma de adsorção de IgG em SBA 15 e SBA 15 com zircônio (SBA 15 Zr-5, SBA 15 Zr-10 e SBA 15 Zr-20).

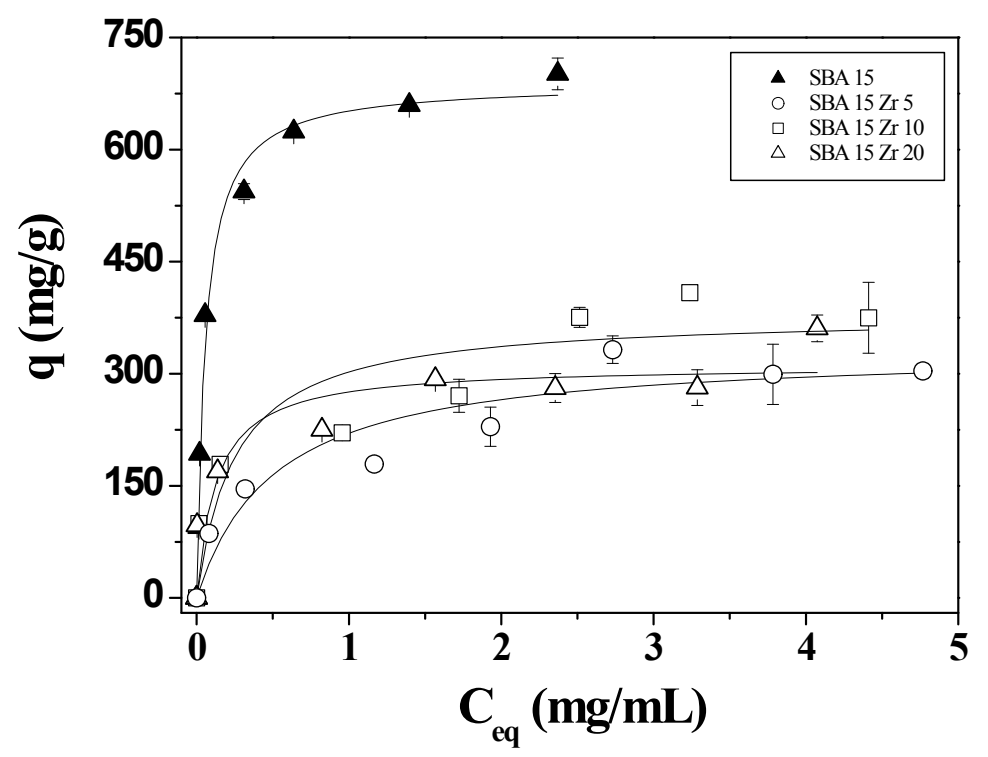

\section{CONCLUSÃO}

Diante dos ensaios realizados e dos dados obtidos, concluiu-se que a modificação da acidez da SBA-15 influenciou na adsorção da proteína. O seu aumento desfavoreceu a adsorção de IgG. A adsorção também sofreu influência do $\mathrm{pH}$ e do pI característico da proteína. O modelo de Langmuir se ajustou aos dados experimentais. Para todos os ensaios o adsorvente com melhores resultados para adsorção de IgG foi o SBA 15 sem zircônio em sua síntese.

\section{REFERÊNCIAS}

BRESOLIN, I.T., SOUZA, M.C.M., BUENO, S.M.A., 2010. A new process of IgG purification by negative chromatography: adsorption aspcets of human serum proteins onto $\omega$-aminodecyl-agarose. Journal Chromatography B, v. 878, p. 2087-2093.

BURNOUF, T.; RADOSEVICH, M. Affinity chromatography in the industrial purification of plasma proteins for therapeutic use. J. Biochem. Biophys. Meth.. v. 49, p. 575-586, 2001. 
FULVIO, P.F., PIKUS, S., JARONIEC, M., 2005. Tailoring properties of SBA-15 materials by controlling conditions of hydrothermal synthesis. Journal of Materials Chemistry. 15, 5049-5053.

SANTOS, S.M.L., CECÍLIA, J.A., VILARRASA, E., JUNIOR, I.J.S., RODRÍGUEZCASTELLÓN, E., AZEVEDO, D.C.S., 2013. Síntese e caracterização de sílicas mesoporosas para a adsorção de biomoléculas modelo (BSA, Lisozima e Celulase).

TSONCHEVA, T., ROSENHOLM, J., TEIXEIRA, C.V., DIMITROV, M., LINDEN, M., MINCHEV, C., 2006. Preparation, characterization and catalytic behavior in methanol decomposition of nanosized iron oxide particles within large pore ordered mesoporous silicas. Microporous and Mesoporous Materials. 89, 209-218. 